\title{
Anti-oxidant, skin whitening, and antibacterial effects of Canavalia gladiata extracts
}

\author{
Ho Chan Kim*, Hae Gang Moon*, Yeong Cheol Jeong*, Jung Up Park, Young Ran Kim \\ College of Pharmacy and Research Institute of Drug Development, Chonnam National University, Gwangju, Korea
}

Received October 25, 2017

Revised November 13, 2017

Accepted December 1, 2017

Corresponding author

Young Ran Kim

College of Pharmacy and Research

Institute of Drug Development,

Chonnam National University, 77

Yongbong-ro, Buk-gu, Gwangju

61186, Korea

Tel: +82-62-530-2923

Fax: +82-62-530-2949

E-mail: kimyr@jnu.ac.kr

*These authors contributed equally to this work.
Canavalia gladiata, a Chinese medicine known as sword bean, has been traditionally used for anti-inflammatory and anti-oxidant properties. This study evaluated the pharmacologic effects of C. gladiata on anti-oxidant, skin whitening, and antibacterial activities. The $80 \%$ ethanol extracts were prepared from ripe or unripe $C$. gladiata. We also made activity comparison between ripe and unripe $C$. gladiata. DPPH and nitro blue tetrazolium/xanthine oxidase $(\mathrm{XO})$ assays were used to evaluate the anti-oxidant activity. C. gladiata showed antioxidant effect in a dose dependent manner. Next, mushroom tyrosinase activity was measured to evaluate the skin whitening effect. C. gladiata showed inhibitory effect on tyrosinase activity in a dose dependent manner. $C$. gladiata extracts also inhibited XO activity. In addition, the antibacterial effects were evaluated by using the minimum inhibitory concentration test and disk diffusion assay. C. gladiata showed antibacterial activity to Vibrio vulnificus. In conclusion, C. gladiata showed the anti-oxidant, tyrosinase inhibition, and antibacterial activities. C. gladiata extracts may be useful for the development of skin whitening and anti-bacterial agents.

Keywords: Canavalia gladiata; Anti-oxidant; Skin whitening; Anti-bacterial

\section{INTRODUCTION}

Canavalia gladiate (Leguminosae family) is widely cultivated in tropical regions such as Southeast Asia and other regions. It is called sword bean since its fruits have a shape similar to a straw cutter. It contains components such as urease, canavanine, hemaglutinine, and $C$. gibberellin I and II [1,2]. In folk medicine, its seeds, pods, stems, and roots are known to have efficacy in treating dysentery, nausea, hemorrhoids, sinusitis, back pain, obesity, diarrhea and hiccups [1]. In addition, several studies have reported the effects of $C$. gladiata on allergy [3], inflammation [4,5], cancer [6], gastritis [7], antioxidant [8], and skin whitening [9]. However, there has not been sufficient research to verify the differences between ripe and unripe green sword beans.

The antioxidant activity has recently become a target for product development in the pharmaceutical and cosmetics industry [10]. Sword bean extracts have been reported to have a skin whitening effect [9]. These patents only verified the skin whitening effects of sword bean extract, but few studies discussed the effects in relation to ripeness or unripeness of sword beans.

Recently, Vibrio vulnificus food poisoning has occurred frequently due to the rising water temperature of the sea level in Korea [11]. In order to prevent food poisoning caused by fish and shellfish including summer sashimi, chlorine- and

This is an Open Access article distributed under the terms of the Creative Commons Attribution Non-Commercial License (http://creativecommons.org/licenses/by-nc/4.0) which permits unrestricted noncommercial use, distribution, and reproduction in any medium, provided the original work is properly cited. Copyright $@$ Medical Biological Science and Engineering. 
oxygen-based disinfectants are used in fish farms. However, the problem of residual toxicity due to these chemical disinfectants has been raised. In this situation, the natural antimicrobial agent using sword bean extract is expected not only to prevent food poisoning caused by $V$. vulnificus, but also to increase the freshness of fish and shellfish while reducing the toxicity. Studies on the antibacterial effect of sword bean extracts against Streptococcus mutans, which is known as a causative organism of dental caries, are insufficient. Additional verification of the antibacterial effect of sword bean extracts against $S$. mutans will determine the clinical applicability of sword bean extracts.

In this study, the anti-oxidant effect of sword beans was tested by DPPH and nitro blue tetrazolium (NBT)/xanthine oxidase (XO) assay, focusing on the differences in the antioxidant activity between ripe and unripe sword beans. In addition, the skin whitening effect experiments were conducted by the in vitro mushroom tyrosinase activity method. We also investigated the differences in the $\mathrm{XO}$ inhibitory activity between ripe and unripe sword beans by the in vitro XO method. Finally, the antibacterial effects of ripe and unripe sword beans were studied on Vibrio species and the antibacterial activity against $S$. mutans.

\section{MATERIALS AND METHODS}

\section{Experimental materials}

\section{1) Materials}

Ripe and unripe $C$. gladiata (each $2 \mathrm{~kg}$ ) supplied from Hwanggeum Nongwon Co. (Jangheung, Korea) were extracted twice with 80\% ethanol in a heating mantle (MSE109; Hanil Lab Tech Co., Ltd., Yangju, Korea) and the extracts were filtered. The extracts were concentrated with a rotary vacuum evaporator (N-1000; EYELA, Tokyo, Japan) and the concentrates were lyophilized using a freeze dryer (TFD8503; Ilshin Lab Co., Ltd., Busan, Korea). The yields of ripe and unripe $C$. gladiata extracts were $23.13 \%$ and $5.45 \%$, respectively.

\section{2) Used strains and culture media}

The strains used in this experiment were $V$. vulnificus MO624/O [12,13], Vibrio cholerae N16961 [14], and S. mutans ATCC 25175 [15]. These strains were pre-cultured in LB Broth
( $1 \%$ tryptone, $0.5 \%$ yeast extract, $1 \%$ sodium chloride, $\mathrm{pH} 7.0 \pm$ 0.2) (LB Broth; Becton Dickinson, East Rutherford, NJ, USA) or brain heart infusion (BHI) supplemented with $5 \%$ sucrose (BHI Browth; Becton Dickinson).

\section{Experimental methods}

\section{1) Measurement of the DPPH radical scavenging activity}

The antioxidant capacity was analyzed by measuring their free radical scavenging activity by using the 2, 2-diphenyl1-picrylhydrazyl (DPPH; $0.2 \mathrm{mM}$ ) (Sigma-Aldrich Chemical Co., St. Louis, MO, USA). Butylated hydroxyanisole (ascorbic acid; $10 \mu \mathrm{g} / \mathrm{mL}$ ) (Sigma-Aldrich Chemical Co.) was used as a positive control. The sward bean extracts and other drugs dissolved in methanol were mixed with $0.2 \mathrm{mM} \mathrm{DPPH}$ solution (1:1 ratio), and incubated in the dark at room temperature for 30 minutes. Absorbances were measured at $470 \mathrm{~nm}$ using an ELISA microplate reader (ELx 808; BioTek Instruments, Inc., Winooski, VT, USA) [16].

2) NBT/XO (superoxide scavenging activity) measurement Hypoxanthine, ethylenediaminetetraacetic acid (EDTA), NBT and XO were purchased from Sigma-Aldrich Chemical Co. Potassium phosphate buffer (pH 7.4, $1 \mathrm{M}$ ) was purchased from Bio-Solution (Suwon, Korea). Superoxide produced while $\mathrm{XO}$ causes hypoxanthine to convert to uric acid reacts with NBT forming NBT-Diformazan. At this time, superoxide scavenging capacity can be confirmed through the degree of the increase in absorbance [17].

Potassium phosphate buffer with $0.6 \mathrm{mM}$ hypoxanthine, 1 mM EDTA, and $0.2 \mathrm{mM} \mathrm{NBT}$ was prepared. Ripe or unripe $C$. gladiata extract $(10 \mu \mathrm{L}), 140 \mu \mathrm{L}$ of buffer, $50 \mu \mathrm{L}$ of $0.1 \mathrm{U} / \mathrm{mL}$ $\mathrm{XO}$ were added to each well of 96-well plates (SPL Life Science Co., Pocheon, Korea). The samples were incubated in the dark at $37^{\circ} \mathrm{C}$ for 20 minutes, and the absorbance was measured at $490 \mathrm{~nm}$ using an ELISA microplate reader. Allopurinol (SigmaAldrich Chemical Co.) was used as the positive control.

3) Measurement of the skin whitening effect of $C$. gladiata through the in vitro mushroom tyrosinase activity

In vitro mushroom tyrosinase activity was measured in order to confirm the skin whitening effects of ripe and unripe $C$. gladiata extracts. The extracts were treated with tyrosinase (25 $\mathrm{U} / \mathrm{mL}$; Sigma-Aldrich Chemical Co.) in an incubator at $37^{\circ} \mathrm{C}$ for 
10 minutes. In addition, the samples were treated with L-DOPA (50 mM; Sigma-Aldrich Chemical Co.) in the dark at $37^{\circ} \mathrm{C}$ for 10 minutes, and the absorbance was measured at $490 \mathrm{~nm}$ using an ELISA microplate reader. Ascorbic acid $(20 \mu \mathrm{g} / \mathrm{mL})$ was used as a positive control.

\section{4) $\mathrm{XO}$ activity of $C$. gladiata}

Xanthine, XO, and allopurinol were purchased from SigmaAldrich Chemical Co. To measure XO activity, the amount of xanthine converted to uric acid was compared using measurements of absorbance. After $77 \mu \mathrm{L}$ of $100 \mathrm{mM}$ potassium phosphate buffer ( $\mathrm{pH} 7.4$ ) and $50 \mu \mathrm{L}$ of ripe and unripe $C$. gladiata extract were added to ultraviolet-transparent 96 well plates (Corning Incorporated, NY, USA), $7 \mu \mathrm{L}$ of XO (200 mU/ $\mathrm{mL}$ ) was added and the solutions were incubated in the dark at $37^{\circ} \mathrm{C}$ for 10 minutes in an incubator (Benchmark, Angleton, TX, USA). Then, $66 \mu \mathrm{L}$ of $0.4 \mathrm{mM}$ xanthine was added and the solutions were incubated in the dark at $37^{\circ} \mathrm{C}$ for 10 minutes. The absorbance was measured at $290 \mathrm{~nm}$ using an ELISA microplate reader. Allopurinol $(10 \mu \mathrm{M})$ was used as a positive control.

\section{5) Measurement of antibacterial effects of $C$. gladiata}

To confirm the antibacterial effects of ripe and unripe $C$. gladiata, the microplate dilution method [18] was performed. $V$. vulnificus and $V$. cholerae were cultured in LB Broth and $S$.

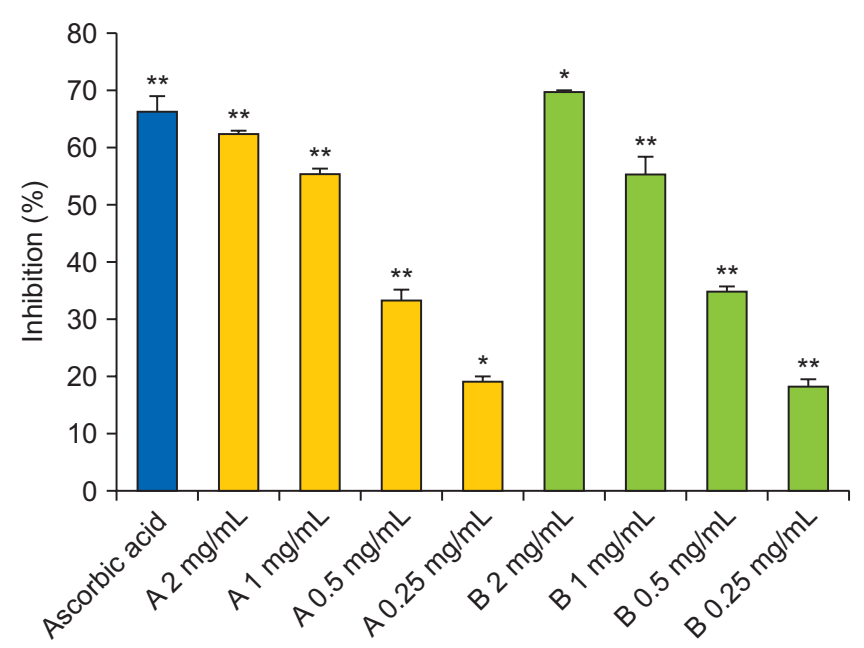

Fig. 1. Anti-oxidant activity of ripe and unripe Canavalia gladiata extracts. C. gladiata extracts dissolved in methanol were mixed with DPPH (0.2 mM in methanol) in 96 well plate for 30 minutes and then the absorbance was measured at $490 \mathrm{~nm}$ using an ELISA microplate reader. Ascorbic acid $(10 \mu \mathrm{g} / \mathrm{mL})$ was used as a positive anti-oxidant drug. ${ }^{*} p<0.05,{ }^{* *} p<0.01$ compared with the untreated group. A: ripe $C$. gladiata, B: unripe C. gladiata. mutans was grown in $\mathrm{BHI}$ broth containing $5 \%$ sucrose.

We also measured the antibacterial activity by the paper disk diffusion method. Sterilized paper disks (6 $\mathrm{mm}$ diameter) were placed on the plate, and each of the samples were dripped [19].

\section{Statistical analysis}

All experiments were repeated 3 times or more and statistical analysis was performed with the significant results of three experiments among them. The experiment results were expressed as the mean \pm standard error, and statistical differences were determined using the Student's t-test. p-value $<0.05$ was considered statistically significant.

\section{RESULTS}

\section{Antioxidant effects through the DPPH radical scavenging activity}

The antioxidant capacity was measured by the reaction of ripe and unripe C. gladiata extracts with DPPH. As a result, dose-dependent antioxidant activity was observed at the concentrations ranging from 2 to $1,0.5$ and 0.25 $\mathrm{mg} / \mathrm{mL}$, and unripe $C$. gladiata showed better antioxidant capacity than ripe $C$. gladiata (Fig. 1). C. gladiata extract at the concentration of $2 \mathrm{mg} / \mathrm{mL}$ showed an antioxidant effect comparable to that of ascorbic acid of the control group (Fig.

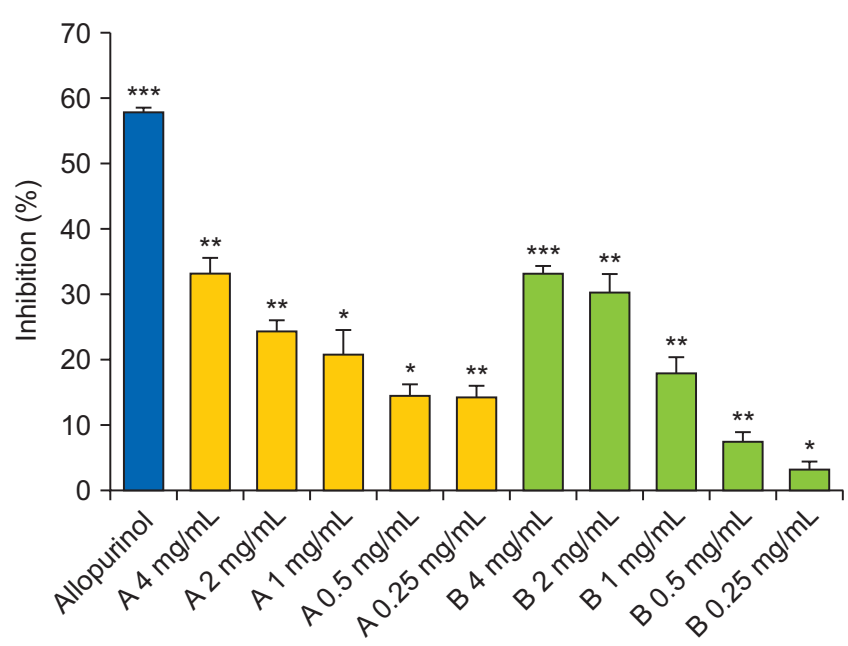

Fig. 2. Anti-oxidant activities of ripe and unripe Canavalia gladiata extracts in nitro blue tetrazolium (NBT)/xanthine oxidase assay. The scavenging potential for superoxide radicals was analyzed via a hypoxanthine/xanthine oxidase generating system coupled with NBT. Allopurinol (10 mM) was used as a positive anti-oxidant drug. ${ }^{*} p<0.05$, ${ }^{* *} p<0.01$, and ${ }^{* * *} p<0.001$ compared with the untreated group. A: ripe C. gladiata, B: unripe C. gladiata. 
1).

\section{Antioxidant effects by reactive oxygen species inhibitory activity}

The NBT/XO assay was performed to verify the reactive oxygen species (ROS) inhibitory activity of ripe and unripe C. gladiata extracts. ROS inhibitory activity was increased in a dose dependent manner at concentrations from $4 \mathrm{mg} /$ $\mathrm{mL}$ to $2,1,0.5$, and $0.25 \mathrm{mg} / \mathrm{mL}$ in both ripe and unripe $C$. gladiata extracts. Unripe $C$. gladiata extracts showed better ROS inhibitory activity than ripe $C$. gladiata extracts (Fig. 2). However, the ROS inhibitory activity of unripe $C$. gladiata extracts was not better than that of Allopurinol (Fig. 2).

\section{Verification of the skin whitening effect through the tyrosinase inhibitory activity}

The tyrosinase inhibitory activity of ripe and unripe sword bean extracts was $33 \%$ and $45 \%$, respectively at $4 \mathrm{mg} / \mathrm{mL}$ (Fig. 3). Ascorbic acid used as the positive control showed tyrosinase inhibitory activity of $68 \%$ on average. In vitro mushroom tyrosinase activity experiments at the final concentrations of $4,2,1,0.5$, and $0.25 \mathrm{mg} / \mathrm{mL}$ of ripe and unripe sword bean extracts, both ripe and unripe sword bean extracts showed tyrosinase inhibitory activity in a dose dependent manner. Based on these experiment results, the

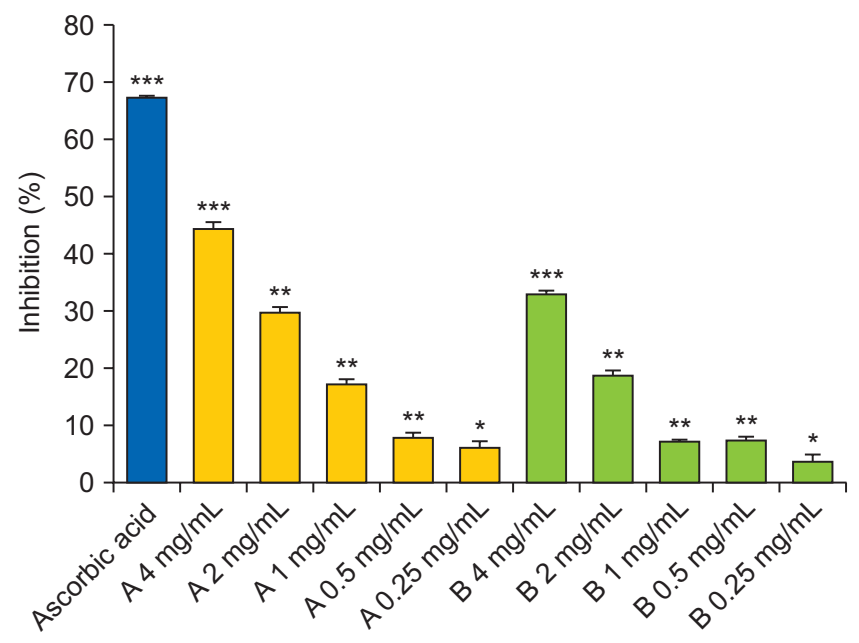

Fig. 3. Effect of ripe and unripe Canavalia gladiata extracts on tyrosinase activity. Ripe and unripe C. gladiata extracts dissolved in Dulbecco's phosphate-buffered saline were mixed with mushroom tyrosinase in 96 well plate and incubated for 10 minutes at $37^{\circ} \mathrm{C}$ and then mixtures were mixed with L-DOPA in the same way. The absorbance was measured at $490 \mathrm{~nm}$ using an ELISA microplate reader. Ascorbic acid $(20 \mu \mathrm{g} / \mathrm{mL})$ was used as positive control. ${ }^{*} p<0.05,{ }^{* *} p<0.01$, and ${ }^{* * *} p<0.001$ compared with the untreated group. A: ripe $C$. gladiata, B: unripe $C$. gladiata. amounts $\left(\mathrm{IC}_{50}\right)$ of ripe and unripe $C$. gladiata extracts required to inhibit the tyrosinase activity by $50 \%$ were determined. The $\mathrm{IC}_{50}$ of unripe $C$. gladiata extract was $6.1 \mathrm{mg} / \mathrm{mL}$, which was higher than the $\mathrm{IC}_{50}$ of ripe $C$. gladiata extract, $4.3 \mathrm{mg} / \mathrm{mL}$.

\section{XO inhibitory activity}

Ripe and unripe C. gladiata extracts showed the XO inhibitory activities of $35 \%$ and $24 \%$, respectively at $4 \mathrm{mg} /$ $\mathrm{mL}$ (Fig. 4). Allopurinol used as the positive control showed high inhibitory activity of $80 \%$ on average against XO. In vitro $\mathrm{XO}$ activity experiments, ripe and unripe $C$. gladiata extracts inhibited $\mathrm{XO}$ in a concentration dependent manner at final concentrations of 4,2 , and $1 \mathrm{mg} / \mathrm{mL}$.

Based on these experiment results, the amounts of ripe and unripe $C$. gladiata extracts required to inhibit the $\mathrm{XO}$ activity by $50 \%\left(\mathrm{IC}_{50}\right)$ were determined. The $\mathrm{IC}_{50}$ of unripe sword bean extracts was $5.7 \mathrm{mg} / \mathrm{mL}$, and it was lower than the $\mathrm{IC}_{50}$ of ripe sword bean extracts, $8.3 \mathrm{mg} / \mathrm{mL}$.

The antibacterial effects of ripe and unripe $C$. gladiata extracts on $V$. vulnificus, $V$. cholerae and $S$. mutans

To investigate the antibacterial activity of $C$. gladiata extracts against $V$. vulnificus, $V$. cholerae and $S$. mutans, we measured the absorbance after treating each strain with sword bean extracts. As a result, unripe sword bean extract

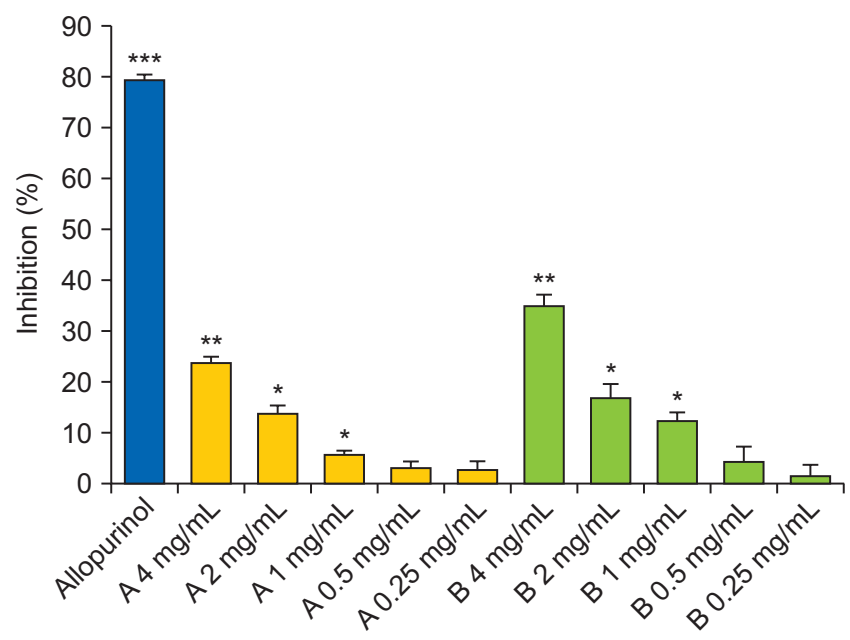

Fig. 4. Effect of ripe and unripe Canavalia gladiata extracts on xanthine oxidase activity. Ripe and unripe C. gladiata extracts dissolved in Dulbecco's phosphate-buffered saline were mixed with xanthine oxidase in 96 well plate and incubated for 10 minutes at $37^{\circ} \mathrm{C}$ and then mixtures were mixed with xanthine. The absorbance was measured at $290 \mathrm{~nm}$ using an ELISA microplate reader. Allopurinol $(10 \mu \mathrm{M})$ was used as a positive control. ${ }^{*} p<0.05,{ }^{* *} p<0.01$, and ${ }^{* * *} p<0.001$ compared with the untreated group. $A$ : ripe $C$. gladiata, B: unripe $C$. gladiata. 
showed an antibacterial effect on $V$. vulnificus at $4 \mathrm{mg} / \mathrm{mL}$ compared to other concentrations (Fig. 5). In contrast, sword bean extracts did not show antibacterial activity against $V$. cholerae and S. mutans (Figs. 6 and 7).

In the disk diffusion assay for $V$. vulnificus, the diameters

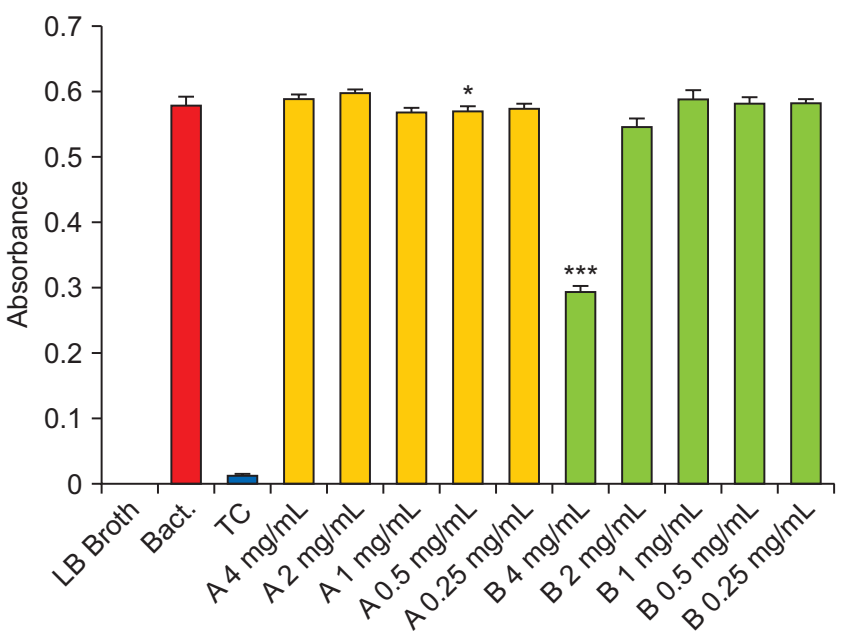

Fig. 5. Antibacterial effect of ripe and unripe Canavalia gladiata extracts on Vibrio vulnificus. V. vulnificus $(90 \mu \mathrm{L})$ cultured in LB Broth was mixed with ripe and unripe $C$. gladiata extracts $(10 \mu \mathrm{L})$ in 96 well microplate. The 96 well microplate was cultured in incubator at $37^{\circ} \mathrm{C}$ overnight. Each growth of bacteria (bact.) was observed by ELISA microplate reader on $630 \mathrm{~nm}$ optical density. Tetracycline (TC, $1 \mu \mathrm{g} / \mathrm{mL}$ ) was used as a positive control. ${ }^{*} \mathrm{p}<0.05$ and ${ }^{* * *} \mathrm{p}<0.001$ compared with the untreated group. A: ripe $C$. gladiata, B: unripe $C$. gladiata.

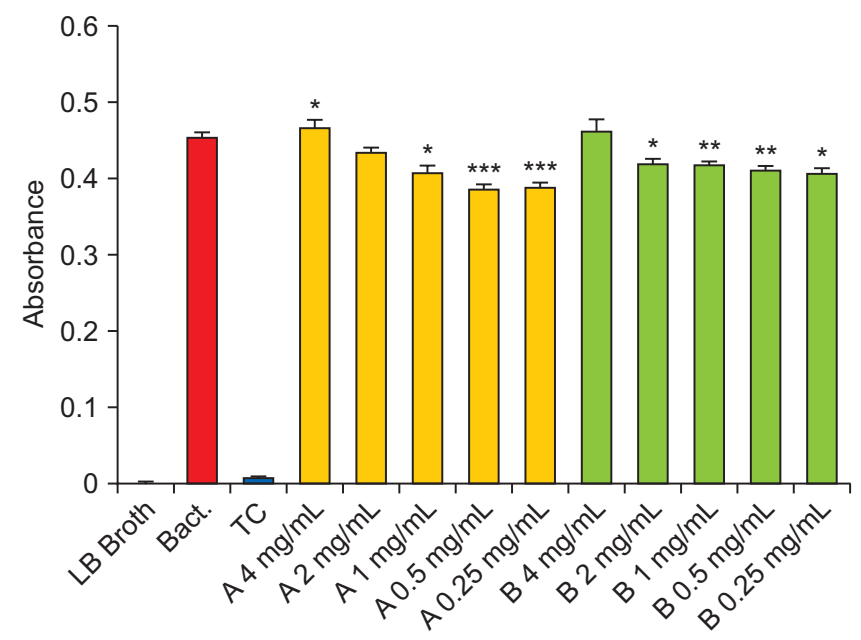

Fig. 6. Antibacterial effect of ripe and unripe Canavalia gladiata extracts on Vibrio cholerae. V. cholerae $(90 \mu \mathrm{L})$ cultured in LB Broth was mixed with ripe and unripe Canavalia gladiata extracts $(10 \mu \mathrm{L})$ in 96 well microplate. The 96 well microplate was cultured in incubator at $37^{\circ} \mathrm{C}$ overnight. Each growth of bacteria (bact.) was observed by ELISA microplate reader on $630 \mathrm{~nm}$ optical density. Tetracycline (TC, $1 \mu \mathrm{g} / \mathrm{mL}$ ) was used as a positive control. ${ }^{*} p<0.05$, ${ }^{*} p<0.01$, and ${ }^{* * *} p<0.001$ compared with the untreated group. A: ripe C. gladiata, B: unripe $C$. gladiata. of growth inhibitory zones were $8 \pm 0.17 \mathrm{~mm}$ and $9 \pm 0.22$ $\mathrm{mm}$, respectively for ripe and unripe sword bean extracts at the concentration of $4 \mathrm{mg} /$ disk (Table 1). The diameters of growth inhibitory zones for ripe and unripe sword bean extracts were $7 \pm 0.31 \mathrm{~mm}$ and $8 \pm 0.28 \mathrm{~mm}$, respectively at the concentration of $4 \mathrm{mg} /$ disk in the culture media for $V$. cholera, compared to the negative control. Growth inhibitory zones were not observed in the culture media for $S$. mutans

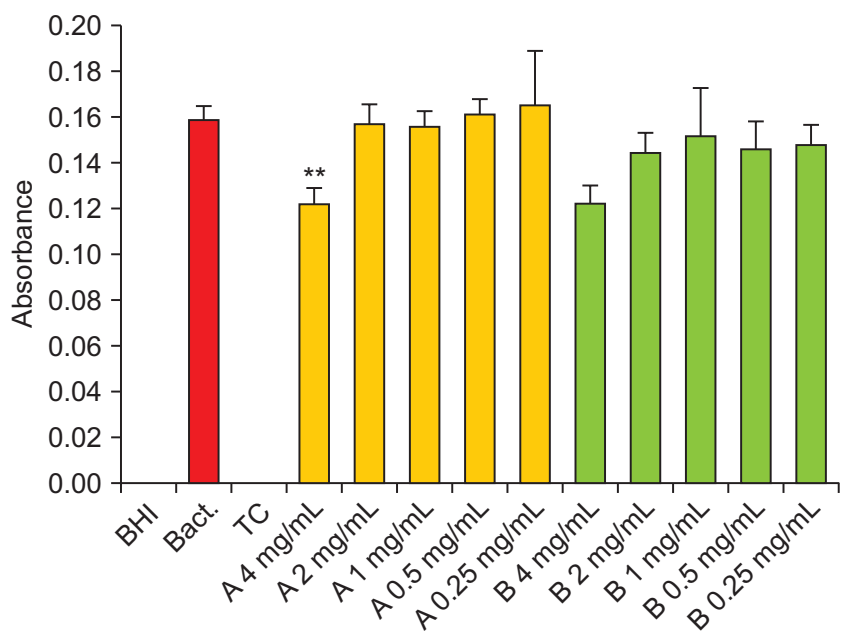

Fig. 7. Antibacterial effect of ripe and unripe Canavalia gladiata extracts on Streptococcus mutans. S. mutans $(90 \mu \mathrm{L})$ cultured in LB Broth was mixed with ripe and unripe $C$. gladiata extracts $(10 \mu \mathrm{L})$ in 96 well microplate. The 96 well microplate was cultured in an incubator at $37^{\circ} \mathrm{C}$ overnight. Each growth of bacteria (bact.) was observed by ELISA microplate reader on $630 \mathrm{~nm}$ optical density. Tetracycline (TC, $1 \mu \mathrm{g} / \mathrm{mL}$ ) was used as a positive control. ${ }^{*} \mathrm{p}<0.05$ and ${ }^{* *} \mathrm{p}<0.01 \mathrm{com}-$ pared with the untreated group. BHI: brain heart infusion, $A$ : ripe $C$. gladiata, B: unripe C. gladiata.

Table 1. Antibacterial activity of Canavalia gladiata extracts against bacterial strains

\begin{tabular}{crccc} 
& & \multicolumn{3}{c}{ Zone of inhibition (mm) } \\
\cline { 3 - 5 } Sample & $\begin{array}{c}\text { Concentration } \\
\text { per disk }\end{array}$ & \multicolumn{3}{c}{ Tested microorganisms } \\
\cline { 3 - 5 } & & $\begin{array}{c}\text { Vibrio } \\
\text { vulnificus }\end{array}$ & $\begin{array}{c}\text { Vibrio } \\
\text { cholerae }\end{array}$ & $\begin{array}{c}\text { Streptococcus } \\
\text { mutans }\end{array}$ \\
\hline Tetracycline & $2 \mu \mathrm{g} /$ disk & $17 \pm 0.08$ & $16 \pm 0.05$ & $23.3 \pm 0.10$ \\
(positive control) & & & & \\
Ripe C. gladiata & $4 \mathrm{mg} /$ disk & $9 \pm 0.22$ & $8 \pm 0.28$ & - \\
& $2 \mathrm{mg} /$ disk & $8 \pm 0.29$ & - & - \\
& $1 \mathrm{mg} /$ disk & - & - & - \\
& $0.5 \mathrm{mg} /$ disk & - & - & - \\
Unripe C. gladiata & $4 \mathrm{mg} /$ disk & $8 \pm 0.17$ & $7 \pm 0.31$ & - \\
& $2 \mathrm{mg} /$ disk & $7 \pm 0.20$ & - & - \\
& $1 \mathrm{mg} /$ disk & - & - & - \\
& $0.5 \mathrm{mg} /$ disk & - & - & - \\
\hline
\end{tabular}

Values are mean \pm standard deviation of three parallel measurements. -: no inhibition zone observed. 

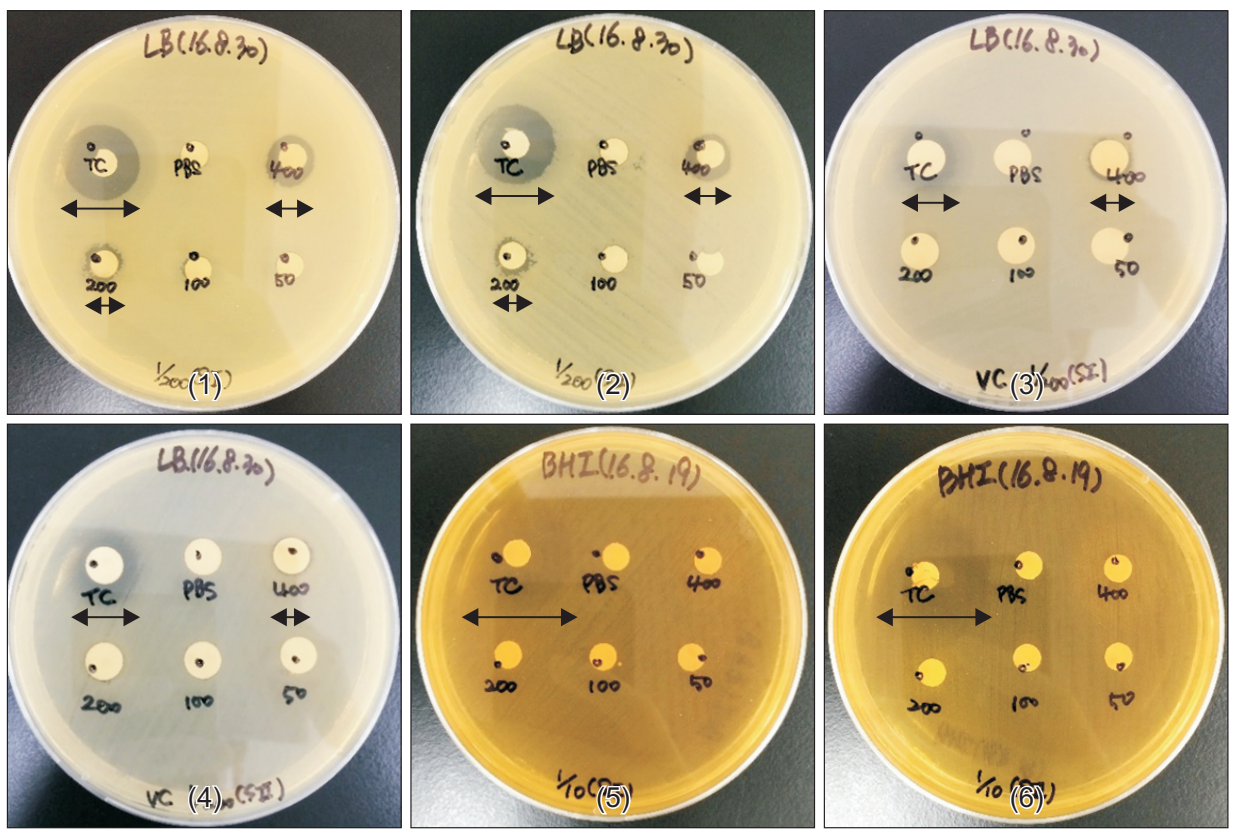

Fig. 8. Inhibition zone of Canavalia gladiata extract against 3 bacterial strains (Vibrio vulnificus, Vibrio cholerae, Streptococcus mutans). V. vulnificus
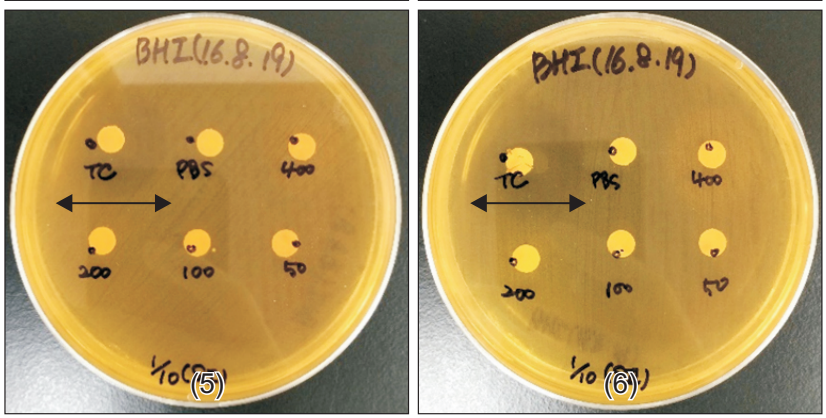
(plates 1 and 2), V. clolerae (plates 3 and 4 ), and $S$. mutans (plates 5 and 6 ) were loaded on the plates. Disks with ripe or unripe $C$. gladiata extracts were dropped on the plates. Each $20 \mu \mathrm{L}$ was dropped on the plates: tetracycline (1 $\mu \mathrm{g} / \mathrm{mL})$, DPBS, C. gladiata extracts (4, 2, 1 and $0.5 \mathrm{mg} / \mathrm{mL}$ ). Tetracycline was used as a positive control drug and DPBS was for a solvent control. LB: LB Broth, BHI: brain heart infusion.

(Fig. 8). The diameter of each growth inhibitory zone is shown in Table 1 . Unlike the MIC measurement, $C$. gladiata extracts showed antibacterial activity against $V$. vulnificus and $V$. cholerae at the concentration of $4 \mathrm{mg} /$ disk. On the other hand, no growth inhibitory zone was observed in the case of $S$. mutans.

\section{DISCUSSION}

Recently, C. gladiata is a natural product having attracting attention as an anti-aging and skin-whitening material. In this study, we confirmed anti-aging, skin whitening, and antibacterial activities of $C$. gladiata and investigated the differences in efficacy between ripe and unripe sword beans. With respect to antioxidant effects, it was confirmed that both ripe and unripe $C$. gladiata extracts have antioxidant effects in a concentration dependent manner. Unripe $C$. gladiata extract showed better antioxidant effects than ripe $C$. gladiata extract. In terms of skin whitening effects, it was found that both ripe and unripe $C$. gladiata extracts had positive effects, and ripe $C$. gladiata extract showed better skin whitening effects than unripe $C$. gladiata extract. For XO inhibitory effects, both ripe and unripe $C$. gladiata extracts exhibited $\mathrm{XO}$ inhibitory effects in a concentration dependent manner, and unripe $C$. gladiata extract showed better inhibitory effects than ripe $C$. gladiata extract. In terms of antibacterial effects, only unripe $C$. gladiata extract at the concentration of $4 \mathrm{mg} / \mathrm{mL}$ had the antibacterial effect of $50 \%$ inhibition in the culture media for $V$. vulnificus. The results of the disk diffusion assay showed significant antibacterial effects on $V$. vulnificus and $V$. cholerae, but no significant antibacterial effect on $S$. mutans was observed.

Therefore, $C$. gladiata is thought to have sufficient potential for development as a raw material for dietary supplements and cosmetics through its antioxidant, skin whitening, and antibacterial effects. In this respect, it is necessary to verify various pharmacologic activities of $C$. gladiata through additional cell and animal experiments in the future.

\section{CONFLICT OF INTEREST}

No potential conflict of interest relevant to this article was reported.

\section{REFERENCES}

1. Kim CM, Shin MK, Ahn DK, Lee KS. Jungyagdaesajeon [The encyclopedia of oriental herbal medicine]. Seoul: Jungdam Publishing; 1997. p. 1343-6.

2. Author. Compendium of materia medica. Seoul: Eui Seong Dang Publishing Co.; 1994.

3. Kim OK, Chang JY, Nam DE, Park YK, Jun W, Lee J. Effect of Canavalia gladiata extract fermented with aspergillus oryzae on the development of atopic dermatitis in NC/Nga mice. Int Arch Allergy Immunol 2015;168:79-89. 
4. Han SS, Hur SJ, Lee SK. A comparison of antioxidative and anti-inflammatory activities of sword beans and soybeans fermented with Bacillus subtilis. Food Funct 2015;6:2736-48.

5. Ekanayake S, Skog K, Asp NG. Canavanine content in sword beans (Canavalia gladiata): analysis and effect of processing. Food Chem Toxicol 2007;45:797-803.

6. Jeon KS, Na HJ, Kim YM, Kwon HJ. Antiangiogenic activity of 4-O-methylgallic acid from Canavalia gladiata, a dietary legume. Biochem Biophys Res Commun 2005;330:1268-74.

7. Kim OK, Nam DE, You YH, Jun WJ, Lee JM. Protective effect of Canavalia gladiata on gastric inflammation induced by alcohol treatment in rats. J Korean Soc Food Sci Nutr 2013;42:690-6.

8. Byun JS, Han YS, Lee SS. The effects of yellow soybean, black soybean, and sword bean on lipid levels and oxidative stress in ovariectomized rats. Int J Vitam Nutr Res 2010;80:97-106.

9. Chang MI, Kim JY, Kim US, Baek SH. Antioxidant, tyrosinase inhibitory, and anti-proliferative activities of Gochujang added with Cheonggukjang powder made from sword bean. Korean J Food Sci Technol 2013;45:221-6.

10. Hong JK. A study on skin aging caused by free-radical and on efficacy of antioxidant vitamins. Korean J Aesthet Cosmet Soc 2009;7:51-62.

11. Lee KH, Lee SK. Pathophysiology of gout. Korean J Med 2011; 80:251-4.

12. Reddy GP, Hayat U, Abeygunawardana C, Fox C, Wright AC,
Maneval DR Jr, et al. Purification and determination of the structure of capsular polysaccharide of Vibrio vulnificus M0624. J Bacteriol 1992;174:2620-30.

13. Park JH, Cho YJ, Chun J, Seok YJ, Lee JK, Kim KS, et al. Complete genome sequence of Vibrio vulnificus MO6-24/O. J Bacteriol 2011;193:2062-3.

14. Heidelberg JF, Eisen JA, Nelson WC, Clayton RA, Gwinn ML, Dodson RJ, et al. DNA sequence of both chromosomes of the cholera pathogen Vibrio cholerae. Nature 2000;406:477-83.

15. Kitten T, Munro CL, Michalek SM, Macrina FL. Genetic characterization of a Streptococcus mutans Lral family operon and role in virulence. Infect Immun 2000;68:4441-51.

16. Park JU, Kim SJ, Na CS, Choi CH, Seo CS, Son JK, et al. Chondroprotective and anti-inflammatory effects of ChondroT, a new complex herbal medication. BMC Complement Altern Med 2016;16:213.

17. Song HS, Moon HJ, Park BE, Choi BS, Lee DJ, Lee JY, et al. Antioxidant activity and whitening activity of bamboo extracts. Yakhak Hoeji 2007;51:500-7.

18. Oh DR, Kim JR, Kim YR. Genistein inhibits Vibrio vulnificus adhesion and cytotoxicity to HeLa cells. Arch Pharm Res 2010; 33:787-92.

19. Chung JK, Lee JC, Ha DR. Antimicrobial activities of sword bean (Canavalia gladiata) extracts against food poisoning bacteria. J Food Hyg Saf 2014;29:376-82. 